\title{
Student access to the information landscape: A national education evaluation conducted by the New Zealand Education Review Office during 2004/5
}

\author{
Cilla CORLETT \\ Senior Education Analyst \\ Education Review Office \\ New Zealand.
}

\begin{abstract}
The Education Review Office (ERO) undertakes reviews of schools and early childhood centres throughout New Zealand. ERO also undertakes national evaluations. The purpose of each review/evaluation is to help bring about improved educational achievement for young New Zealanders and to provide information to schools, parents, communities and the government to assist decision making. During 2004/5, ERO conducted a national evaluation of student access to the information landscape in schools. The quality of policies, programmes and practices associated with the school library was one focus in this evaluation. The quality of teaching practice (particularly in the areas of student information literacy and in developing positive attitudes towards reading) was also evaluated. This paper gives an outline of the role of ERO, the rationale and purpose of the national evaluation, and the methodology used. It provides some initial discussion of preliminary findings. It also reports on anecdotal feedback received on the process of the evaluation and its impact on participating schools.
\end{abstract}

\section{Student access to the information landscape: a national evaluation}

The role of the Education Review Office in New Zealand education

The Education Review Office (ERO) is a New Zealand government department whose purpose is to evaluate and report publicly on the education and care of students in schools and early childhood services. ERO's findings inform decisions and choices made by parents, teachers, managers, school trustees and others, at the individual school and early childhood level, and at the national level by Government policy makers.

The chief executive of ERO is the Chief Review Officer, who formally designates individual review officers to carry out reviews in schools and early childhood centres. The functions and powers of the Chief Review Officer are described in the New Zealand Education Ac,t 1989. This Act gives the Chief Review Officer the power to initiate reviews and to investigate, report and publish findings on the provision of education to all young New Zealanders. The Chief Review Officer has approximately 120 designated review officers who are located in nine district offices, and a Mäori Review Unit. 


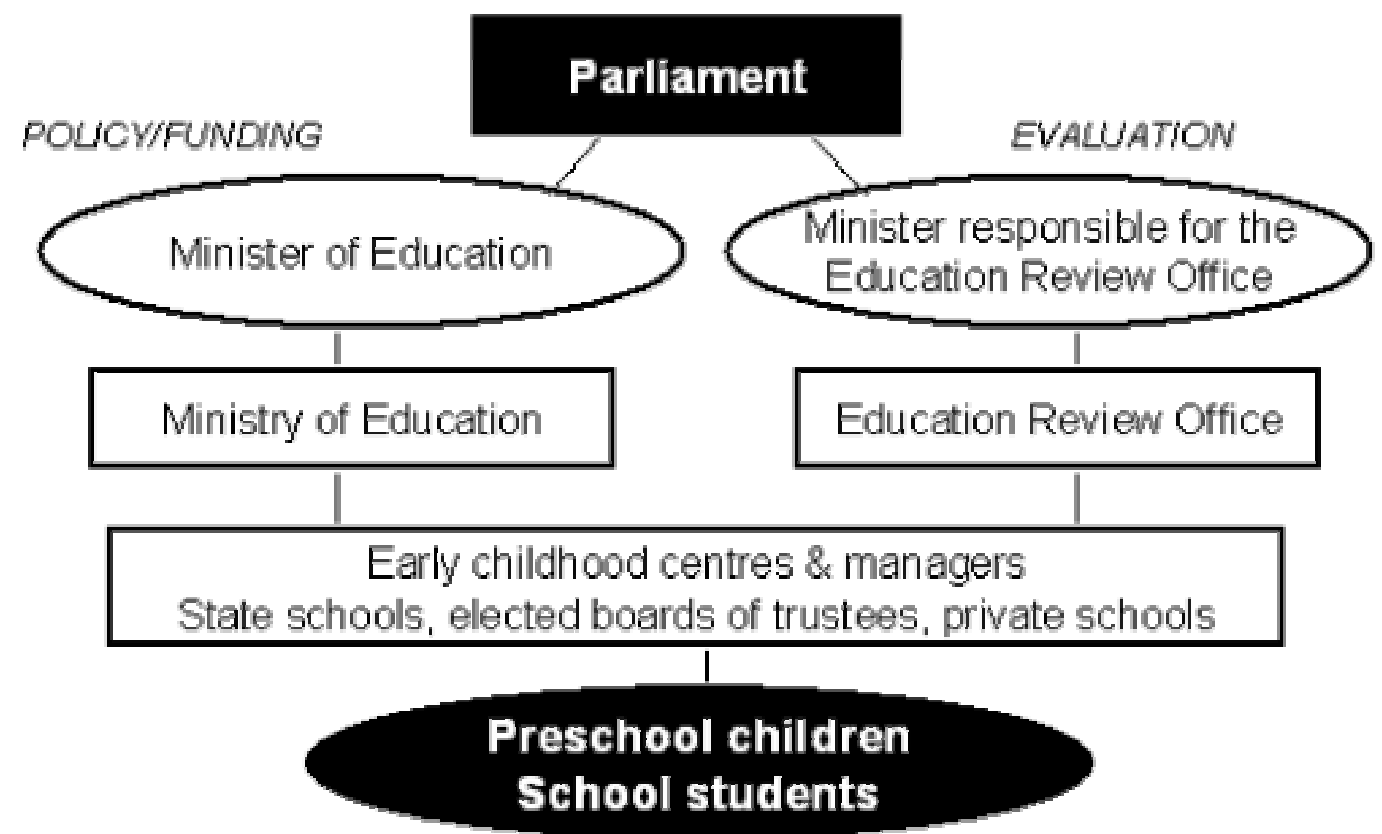

Figure 1 ; The New Zealand early childhood and school education system

ERO carries out different types of reviews - education reviews, homeschool reviews, cluster reviews of education institutions and services, and national evaluations of education issues. It also provides contract evaluation services. In an Education Review, ERO investigates and reports to boards of trustees, managers of early childhood education services and the Government on the quality of education provided for children and students in individual centres and schools.

Schools and early childhood services are reviewed on average once every three years. Reviews are undertaken more frequently where the performance of a school or centre is poor and there are risks to the education and safety of the students. ERO's reports on individual schools and early childhood services are freely available to the public and are a resource for education policy and decision-makers at a national level, for teacher training, for boards of trustees and service managers, and for the academic research communities. The reports are on ERO's website, and can also be obtained from the individual school or centre or from any ERO office.

ERO also evaluates and reports nationally on current education policy and practice. These high level education evaluation reports supply a wide and varied audience with information on topical education issues, stimulate debate on what counts as quality in education policy and practice in New Zealand, and help in the design, implementation and review of policy. ERO's national education evaluations focus on student learning and how school programmes and processes contribute to student learning. All evaluations also have a strong improvement focus and provide information on how programmes and processes can be improved to support increased levels of student achievement. An important part of the process is school self-review and reflection, where ERO poses questions and encourages schools to come up with their own solutions. 


\section{National education evaluation: Student access to the information landscape $(2004 / 5)$}

\section{Purpose/Rationale}

During 2004/2005, the ERO conducted a national evaluation of the extent to which schools provide students with effective access - both physical and intellectual access - to the information landscape. ERO is producing a national report on the evaluation focusing on three broad areas relating to the information landscape in the school context. They are:

- Connection: the infrastructure that brings information resources, collections, formats and services into the learner's environment

- Content: the content of information resources and material available to students

- Capability and Confidence: the skills and behaviours that are required to manage and use the information infrastructure and resources effectively for information literacy, and life-long reading and learning

\section{Context}

The New Zealand Government has stated as key goals that it will:

- improve New Zealanders' skills

- grow an inclusive, innovative economy for the benefit of all

- reduce inequalities in education

The Ministry of Education (2004) sets out four major education sector outcomes related to these goals:

- $\quad$ to provide all New Zealanders with strong foundations for future learning

- to ensure high levels of achievement by all school leavers

- to ensure that New Zealanders engage in learning throughout their lives and develop a highly skilled workforce

- to make a strong contribution to our knowledge base, especially in key areas of national development

The New Zealand Curriculum Framework (Ministry of Education, 1993) links 'access to resources' to student learning opportunities. The Framework also identifies information skills as one of the essential skills groupings and links a number of other skills to the development of information literate, life-long learners (National Library of New Zealand/Ministry of Education, 2002). 
The framework used for this evaluation (Connection, Content, and Capability and Confidence) is based on the premise that students need to be provided with the foundations for functioning as well informed, information literate citizens. To be information literate, students need to learn the appropriate skills, attitudes and values to navigate, manage and use information effectively. Their information literacy development depends to a large extent on quality teaching, which includes the systematic use of an information process model. To support their learning, students, as well as teachers, need to be provided with an information environment and infrastructure that enables effective connections to appropriate, relevant, good quality information and reading resources. Effective student access to the information landscape is dependent on the quality of the school's information infrastructure (connection); the quality of information resources (content); and the quality of teaching in information skills, attitudes and values (confidence and capability).

\section{The school library and learning in the information landscape}

A substantial body of research (for example, Williams, Wavell and Coles, 2001; Hamilton-Pennell et al, 2000), supports the view that as a central feature within the information landscape, a quality school library makes a positive impact on students' achievement. The school library plays a key role in enabling students to develop information literacy by:

- acting as a key resource in the information literacy programme;

- promoting the students' literacy and encouraging them to develop as readers;

- providing staff to support and assist the students and to work collaboratively with the teachers;

- providing a physical learning environment that encourages independent inquiry and discovery;

- selecting information and resources that support all aspects of the curriculum;

- facilitating the students' use of ICT and access to information within and beyond the school; and

- providing user-friendly systems and procedures that facilitate the students' access to and use of information resources (National Library of New Zealand/Ministry of Education, 2002, p.14).

Meaningful impact of the school library supports not only current student education achievement, but also students' opportunities to build strong foundations for future learning. At a national level, this has implications for literacy levels; technology uptake; workforce skills; lifelong learning; an informed citizenry; an information literate society; an innovative economy; social equity; and an inclusive society. 
In the majority of New Zealand schools, the school library is the principal provider of both intellectual and physical student access to the information landscape. Furthermore, the school library is one of the largest, single investments for a school. The current estimated replacement cost for school libraries is approximately \$325 million (Ministry of Education, 2003). The school library is also playing an increasingly important, evolving role in supporting school ICT infrastructure and elearning - another area where the New Zealand government is making major investment.

\section{Evaluation questions}

The overarching evaluation question this project seeks to answer is: How well are schools facilitating student access to the information landscape to support their learning? 'Student access' refers here to both intellectual and physical access. The key questions were:

Connection: Infrastructure

- How effective is the school leadership in providing an appropriate infrastructure that enables students to connect with the information landscape?

- How well does the school library enable the students' connection to the information landscape?

Content: Information Resources

- How well does the content of school information resources (and those the school provides access to through online services) support the needs, interests and abilities of the students?

- How well do the school library's resources (and those it provides access to through online services) support the needs, interests and abilities of the students?

Capability and Confidence: Teaching and Learning

Information Literacy

- How well is the school helping students to develop information literacy?

- How well is the school library supporting information literacy development?

Developing Readers

- How well is the school fostering the students' development of positive attitudes towards reading?

- How well is the school library supporting the students' development of positive attitudes towards reading?

Student Outcomes: Information Literacy/Positive Attitudes to Reading

- To what extent are students acquiring the knowledge, skills and values of information literacy? 
- To what extent are students acquiring positive attitudes towards reading?

The questions form an evaluative framework under the Connection, Content, and Capability and Confidence umbrella. This framework incorporates the school library as well as school management, leadership and teaching. There is a particular focus on students' development of information literacy and positive attitudes to reading.

ERO developed a set of evaluation indicators for each evaluation question to provide an explicit basis for evaluative judgements. The indicators were informed by ERO's own Evaluation Indicators for Education Reviews in Schools (Education Review Office, 2003) which are available on the ERO website www.ero.govt.nz. These indicators are based on ERO's experience over the years in evaluating schools; the findings published in the Ministry of Education's 'best evidence synthesis' on the quality of teaching (Alton-Lee, 2003); and other research. Also informing the evaluation indicators are The School Library and Learning in the Information Landscape: Guidelines for New Zealand Schools developed by the National Library of New Zealand; the framework ERO developed for evaluating e-learning during 2003/4; and current research on the information landscape and school libraries particularly research in the New Zealand context.

The evaluation focused on practices and activities that:

- linked the information landscape to student engagement and learning;

- supported and developed students' intellectual and physical access to quality information

- developed positive learning and information environments that value diversity and inclusion

- reflected high expectations of teachers for the learning and achievement of all students

The evaluative framework was piloted in two schools. The results from piloting provided assurance that the questions and indicators were fit for their intended purpose and would provide a valid basis for review officer judgements.

\section{The reference group and the working group}

\section{Reference Group}

ERO established a Reference Group for this evaluation, comprising Ministry of Education and National Library officials, the president of the School Library Association of New Zealand and a leading academic (Dr Ross Todd) - each with a particular knowledge and interest pertaining to the information landscape in the school context, including school librarianship, information literacy, literacy, and information and communication technologies in education. The purpose of the 
Reference Group was to give advice and support on the methodology, evaluators' training, and data analysis; and to provide peer review during the report-writing phase, after the analysis was completed.

\section{Working Group}

The Working Group was made up of a cross-section of ERO staff with specialist knowledge relevant to this evaluation. The purpose of the Working Group was to:

- check that the approach to this evaluation was fit for purpose;

- provide specialist knowledge relevant to this evaluation;

- facilitate communication with ERO district offices;

- contribute to the evaluation moderation process (both at local and national level); and

- peer review the report.

\section{Review officer training}

Review officers from each ERO area office collected the data in conjunction with the scheduled education reviews of schools. A two-day training programme for the review officers was developed by ERO with input from both the project reference and working groups. The training was designed to achieve reviewer agreement on acceptable benchmarks for the evaluation.

\section{Sample characteristics}

At the time of writing (15 April 2005), the Analysis and Policy unit of ERO had received data from the evaluation of 265 schools. The expected sample size of 330 is 12 percent of the total number of New Zealand schools. Further details on the sample characteristics (school type, roll size, locality, and socio-economic rating) will be available once the full sample is achieved.

\section{Data collection}

ERO collected the data from early October 2004 to mid-April 2005. ERO made initial contact with each participating school to notify it that the review of the school's information landscape would also be undertaken.

Data collection during the time of the school review included the following activities:

- interviews with principal / senior management team

- interviews with library team members 
- interviews with teachers with responsibility for school ICT and elearning coordination

- interviews with teachers

- discussion with students

- school library observations

- classroom observations

- anecdotal evidence from general school review

- reviewing library documentation

- reviewing school documentation and

- reviewing classroom documentation

The data collection process involved gathering information on the school's provision of student access to the information landscape; making a judgment for each evaluation question at the end of each school evaluation; recording these judgments; and providing supporting evidence. An important part of this process was synthesising the evidence collected for this evaluation with all relevant evidence collected during the general school review. Final evaluative judgments were then made within this wider context and in discussion with the review officer team.

Review officers also collected demographic and other factual information on - for example, the school's funding, staffing and resourcing of the school library. This information was recorded for entering into the project database and aggregating for analysis from a national perspective.

\section{Data analysis}

The data (including examples of good and poor practice) were aggregated and analysed using the evaluation questions. Analysis, therefore, focused on student achievement information and the quality of schools' leadership, policies, programmes, resources and practices for meeting the individual and diverse needs of all students for their information literacy development and their development as life-long readers.

\section{Discussion of methodological approach}

\section{Reliability}

ERO took the following steps to support inter-rater reliability (that is, consistent evaluative judgments by reviewers) across the country:

- review officers were provided with an evaluative framework to use as a consistent basis for making evidential judgments 
- review officers were provided with specific training to carry out the evaluation and this training was focused on achieving a shared understanding of the bases on which the reviewers were to make their evaluative judgments

- review officers triangulated the observable evidence on which they based their evaluative conclusions - that is, they supported each evaluative judgement with at least three forms of evidence

- at a local level, noted sources of evidence of all returns were checked against the conclusions reached by the original reviewer

- at a national level, noted sources of evidence of a random sample of the returns were checked against the conclusions reached by the original reviewer and

- a team of trained moderators checked the consistency of reviewer judgements both within ERO regional areas and nationally. The moderation group met twice and at each meeting checked two evidential files for each of the five ERO Areas (20 in total). For each evidential file, they followed guidelines for reliability, content validity, internal validity, evidential base and transparency checking.

By conducting the evaluation in conjunction with ERO education reviews, the reviewers were provided with current information on each school's context and performance.

\section{Validity}

The data collection tools, developed to guide review officers in their data collection and assessment for this evaluation, were valid to the extent that they measured what they were intended to measure. The input of the external reference group of experts; current best evidence synthesis research on the quality of teaching; bench-marking through piloting the framework and review officer training; and the moderation process all served to strengthen the validity of the evaluation tools and processes.

\section{Ethical and legislative considerations}

ERO review officers collected all the data for the evaluation within the normal course of their review activities. They are bound by the legislative framework for the conduct of reviews as set out in the New Zealand Education Act 1989 and a code of ethical conduct for review officers (Education Review Office, 1993).

Within the context of this evaluation, data collected regarding the quality of teaching will not be made available to any third party at the individual level. Consistent with this, data will not be made available for performance assessment and other purposes that would require the use of individually identifiable data. 


\section{Nature of stakeholder relationships}

The key purpose of this evaluation was to provide useful and reliable information for the future development of education policy and practice. As well as being reliable and valid, the evaluation needed to have credibility with identified audiences and stakeholders. Identified stakeholders included:

- The Minister responsible for the Education Review Office

- The Associate Minister of Education (Mäori Education)

- The Minister for the National Library

- Teachers with library responsibility/trained teacher-librarians

- School library managers/school librarians and other school library staff

- Teachers/managers with responsibility for school-wide ICT development and e-learning

- School principals

- Classroom teachers

- School boards of trustees

- National Library of New Zealand School Services

- Ministry of Education officials

- Te Puni Kökiri Ministry of Mäori Development

- the School Library Association of New Zealand

- the Library and Information Association of New Zealand

- Teacher education providers

- Education academics

- Parents/school communities

- The New Zealand Teachers Council and

- Teachers' associations and unions

\section{Reporting}

ERO undertakes to write national education reports that are accessible (content wise), relevant and have credibility with all stakeholders. The evaluation findings will be presented and disseminated to ensure the optimisation of use and usefulness of the evaluations. The report will provide:

- Schools with information on how to maximise the effectiveness of their practices and activities to improve student access to the information landscape

- Parents with information on the quality of schools' practices and activities to improve student access to the information landscape and

- Government with single case and aggregated information (identifying any system issues) on the quality of schools' practices and activities to improve student access to the information landscape

The report will make recommendations or suggest next steps for moving forward, which may include suggestions for further research. While it will present examples of both good and poor practice, the report will be placed within a growth 
framework with a focus on the modeling of good practice. ERO plans to publish a companion volume of good practice examples and case studies to follow the report.

The report is required to be with the Minister (responsible for the Education Review Office) by 30 June 2005. The Minister will determine how and when the report will be released. Following release, ERO will send copies to the stakeholders identified above. The final report will be publicly available in both hard copy format and on the ERO website.

\section{Preliminary observations}

Preliminary findings indicate that the schools did well overall in:

- providing appropriate infrastructure to enable students to connect with the information landscape

- providing access to information resources that effectively support the needs, interests and abilities of the students

Likewise, school libraries did well overall in:

- enabling the students' connection to the information landscape

- providing/providing access to information resources that effectively support the needs, interests and abilities of the students (content)

Both the schools - and school libraries specifically - did well in fostering the students' development of positive attitudes towards reading. Preliminary findings indicate that students had acquired positive attitudes towards reading to a great extent.

Schools did not do so well in helping students to develop information literacy skills. School libraries also, did not fare so well in supporting information literacy development. Preliminary findings indicate that students had acquired the knowledge, skills and values of information literacy to a limited extent.

However, these findings are based on an aggregation of primary and secondary school results. The final analysis and report will treat primary and secondary schools separately because of their very different structures in the New Zealand context.

\section{Evaluation process}

ERO has received feedback on some of the impacts of the 'information landscape evaluation' process itself. Review officers reported that they have generally enjoyed the project as it led to all aspects of teaching and learning in schools and provided a good basis for professional discussion and review. 
In addition, schools reported that the pre-evaluation documentation is useful. They found that the evaluation questions and survey useful as self-review tools that enabled them to prepare well for their evaluations. Some schools not being reviewed this year have requested copies of the evaluation documentation to use for their strategic planning and review.

Many review officers reported that one of main spin-offs of the evaluation is that it raised the consciousness of both review officers and schools about information literacy and the role of the school library in supporting teaching and learning.

\section{References}

Alton-Lee, A. (2003). Quality teaching for diverse students in schooling: best evidence synthesis. Wellington: Ministry of Education.

New Zealand. Education Review Office (1993). Code of ethical conduct for review officers. Wellington. New Zealand. Education Review Office (2003). Evaluation indicators for education reviews in schools. Wellington.

New Zealand. Ministry of Education (1993). The New Zealand curriculum framework. Wellington. New Zealand. Ministry of Education (2003). Unpublished information supplied to ERO.

New Zealand. Ministry of Education (2004). Report for the year ending 30 June 2004. Wellington. National Library of New Zealand and Ministry of Education (2002). The school library and learning in the information landscape: Guidelines for New Zealand schools. Wellington: Learning Media Ltd.

\section{Author Note:}

Cilla Corlett works as a Senior Education Analyst in the Education Review Office, New Zealand. She has a BA in Librarianship and has worked in public, university, special, and school libraries in New Zealand and London, as well as the National Library of New Zealand. In 2001, after gaining a Master of Public Policy, she moved into policy work and was a Senior Policy Analyst in Te Puni Kökiri (The Ministry of Maori Affairs) for two years before joining ERO. She was Project Manager for developing and writing The school library and learning in the information landscape: Guidelines for New Zealand schools (2002) while she was employed by the National Library of New Zealand. She is the Project Manager for the current Education Review Office national evaluation of student access to the information landscape in New Zealand schools. 
Reproduced with permission of the copyright owner. Further reproduction prohibited without permission. 